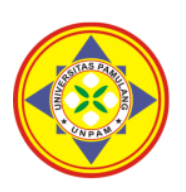
PERKUSS

\title{
PENGARUH STRES KERJA DAN MOTIVASI TERHADAP KINERJA KARYAWAN PADA HOTEL SANTIKA PREMIERE ICE-BSD CITY
}

\author{
1Rizka Putri Amelia, ${ }^{2 *}$ Aden Prawiro Sudarso \\ Universitas Pamulang, Tangerang, Banten, Indonesia \\ *dosen01171@unpam.ac.id
}

\begin{abstract}
Abstrak
Hasil penelitian ini adalah Stres kerja berpengaruh terhadap kinerja karyawan hal ini dapat dilihat dari hasil uji thitung $=0,949$ sedangkan ttabel $=1,662$ (thitung $<$ ttabel) dengan taraf signifikansi $0,345<0,05$, maka H0 diterima dan Ha ditolak. Hasil uji koefisien korelasi yang diperoleh berdasarkan angka koefisien korelasi antara stres kerja dan kinerja karyawan rendah atau sebesar 0.328 . Motivasi berpengaruh signifikan secara parsial antara variabel motivasi tehadap kinerja karyawan dengan diperoleh nilai thitung $>$ ttabel atau $(3,415>1,662)$ hal ini diperkuat dengan nilai signifikansi 0,001 $>0,05$, maka Ho ditolak dan Ha diterima hasil koefisien korelasi secara parsial motivasi terhadap kinerja karyawan memperoleh hasil 0,455 dalam kategori sedang, Secara simultan dengan Uji F terdapat pengaruh yang positif dan signifikan secara bersama-sama antara variabel stress kerja dan motivasi terhadap kinerja karyawan dari nilai yang diperoleh $\mathrm{F}$ hitung $>\mathrm{F}$ table $11,660>3,10$ serta memiliki pengaruh yang sedang yaitu 0,464 .
\end{abstract}

Kata Kunci: Stres Kerja, Motivasi, Kinerja Karyawan.

\section{Abstract}

The results of this study are job stress has an effect on employee performance, this can be seen from the test results tcount $=0.949$ while ttable $=1.662$ (tcount $<$ ttable) with a significance level of $0.345<0.05$, then $\mathrm{HO}$ is accepted and $\mathrm{Ha}$ is rejected. The result of the correlation coefficient test obtained is based on the correlation coefficient between job stress and employee performance is low or 0.328. Motivation has a partially significant effect between motivation variables on employee performance by obtaining tcount $>$ ttable or $(3,415>1,662)$ this is reinforced by a significance value of 0.001>0.05, so Ho is rejected and Ha is accepted as partially as a result of the correlation coefficient of motivation on employee performance obtained results 0.455 in the medium category, Simultaneously with the F test there is a positive and significant effect jointly between work stress and motivation variables on employee performance from the value obtained $F$ count $>F$ table 11.660 $>3.10$. and has a moderate effect, namely 0.464 .

Keywords: Job Stress, Motivation, Employee Performance.

\section{PENDAHULUAN}

Manajemen sumber daya manusia merupakan bagian dari manajemen keorganisasian yang memfokuskan diri pada unsur sumber daya manusia atau bisa di katakan suatu proses yang terdiri dari perencanaan, pengorganisasian, pemimpin dan pengendalian kegiatan sumber daya manusia dan sumber daya manusia lainnya untuk mencapai tujuan yang telah ditetapkan. Sedangkan Manjemen Sumber Daya Manusia menurut A.A. Anwar Prabu Mangkunegara (2013:2), dapat didefinisikan sebagai suatu pengelolaan dan pendayagunaan sumber daya yang ada pada individu (karyawan) pengelolaan dan pendayagunaan tersebut dikembangan secara maksimal didalam dunia kerja untuk mencapai tujuan organisasi pengembangan individu karyawan.

Selama ini dalam era globalisasi perusahaan ataupun lembaga usaha pemerintahan maupun swasta di tuntut untuk lebih memaksimalkan tingkat kinerja dalam sebagai hal,namun perusahaan seringkali melupakan bahwa ada factor stres kerja dan motivasi yang mempengaruhi hal itu memacu pada teori hinarki kebutuhan, kebutuhan manusia dibagi kedalaman beberapa klasifikasi di 
antaranya kebutuhan fisiologi, kebutuhan keamanan, kebutuhan berkelompok, kebutuhan penghargaan, dan kebutuhan aktualisasi diri (Mashlow), maka tidaklah heran jika motivasi sangat berpengaruh terhadap sikap seorang dalam menentukan kinerjanya karena tingkat kinerja karyawan merupakan hasil proses yang absurt berasal dari diri karyawan itu sendiri (internal) maupun dari faktor-faktor dari luar (eksternal). Usaha dalam meningkatkan kinerja karyawan ialah dengan memperhatikan stres kerja dan motivasi yang ada dalam diri karyawan tersebut. Stres merupakan suatu kondisi keadaan seseorang mengalami ketegangan karena adanya kondisi yang mempengaruhinya, kondisi tersebut dapat diperoleh dari dalam dan luar diri. Stres dapat menimbulkan dampak yang negatif terhadap keadaan psikologis dan biologis bagi karyawan.

\section{TINJAUAN PUSTAKA}

1. Stress Kerja

Keenan dan Newton (dalam Wijono, 2007) berpendapat bahwa stress kerja merupakan perwujudan dari kekaburan peran, konflik peran dan beban kerja yang berlebihan. Kondisi ini selanjutnya akan dapat mengganggu prestasi dan kemampuan individu untuk bekerja.

Menurut Kavaganh, Hurts dan Rose (1990), stress kerja merupakan suatu ketidakseimbangan persepsi individu tersebut terhadap kemampuannya untuk melakukan tindakan. Berdasarkan pendapat para ahli diatas, dapat disimpulkan bahwa stress kerja adalah suatu kondisi ketegangan yang mempengaruhi emosi, proses berfikir, dan keadaan fisik seseorang dimana ia terpaksa memberikan tanggapan melebihi kemampuan penyesuaian dirinya terhadap suatu tuntutan eksternal atau lingkungan kerja.

2. Motivasi Kerja

Menurut Mangkunegara, (2000) motivasi kerja didefinisikan sebagai kondisi yang berpengaruh membangkitkan, mengarahkan dan memelihara perilaku yang berhubungan dengan lingkungan kerja. Rivai (2004) mengatakan motivasi adalah : sebagai suatu kondisi yang menggerakkan manusia kearah suatu tujuan tertentu; suatu keahlian dalam mengarahkan karyawan dan perusahaan agar mau bekerja secara berhasil, sehingga keinginan karyawan dan tujuan perusahaan sekaligus tercapai; sebagai inisiasi dan pengarahan tingkah laku; sebagai energi untuk membangkitkan dorongan dalam diri; sebagai kondisi yang berpangaruh membangkitkan mengarahkan dan memelihara perilaku yang berhubungan dengan lingkungan kerja.

Berdasarkan pendapat para ahli di atas, dapat disimpulkan bahwa motivasi merupakan suatu dorongan kebutuhan dalam diri pegawai yang perlu dipenuhi agar pegawai tersebut dapat menyesuaikan diri terhadap lingkungannya, dan yang menggerakkan pegawai agar mampu mencapai tujuannya

\section{METODE PENELITIAN}

Tempat pelaksanaan penelitian ini di lakukan di Hotel Santika Premiere ICE BSD City beralamatkan di Jl. BSD Grand Boulevard, BSD City - Tangerang No. Telephone: (62 - 21) 80634899 Fax: (62 - 21) $8063 \quad 4888 \quad$ Email: bsdcity.icepremiere@santika.com .

Waktu Penelitian. Penelitian dilaksanakan selama tiga bulan terhitung dari bulan Desember 2019 sampai dengan bulan Februari 2020 hingga tercukupi kebutuhan data dan informasi. Populasi dalam penelitian ini adalah seluruh karyawan Hotel Santika Premiere ICE BSD City yang berjumlah 88 karyawan. Dalam sampel yang diambil sebagai responden yaitu para karyawan dengan teknik sampling yang memberikan peluang sama bagi setiap anggota populasi untuk dipilih menjadi sampel. Sampel adalah subset dari populasi, terdiri dari beberapa anggota populasi (Ferdinand, 2013). 
populasi yang disebut sampel. Karena populasi dalam penelitian ini sangat banyak dan tidak diketahui jumlah pastinya, maka diambil beberapa sampel untuk mewakili populasi tersebut.

\section{HASIL DAN PEMBAHASAN}

Tabel 1. Uji Multikolonieritas

Coefficients ${ }^{a}$

\begin{tabular}{|c|c|c|c|c|c|c|c|}
\hline \multirow[t]{2}{*}{ Model } & \multicolumn{2}{|c|}{ Unstandardized Coefficients } & \multirow{2}{*}{$\frac{\text { Standardized Coefficients }}{\text { Beta }}$} & \multirow[b]{2}{*}{$\mathrm{T}$} & \multirow[b]{2}{*}{ Sig. } & \multicolumn{2}{|c|}{ Collinearity Statistics } \\
\hline & B & Std. Error & & & & Tolerance & VIF \\
\hline (Constant) & 25,476 & 3,700 & & 6,886 & ,000 & & \\
\hline Stres $\operatorname{kerja}(\mathrm{X} 1)$ & ,095 & , 100 & 110 & 949 & ,345 & 693 & 1,444 \\
\hline Motivasi(X2) & 306 & ,090 & ,394 & 3,415 & 001 & 693 & 1,444 \\
\hline
\end{tabular}

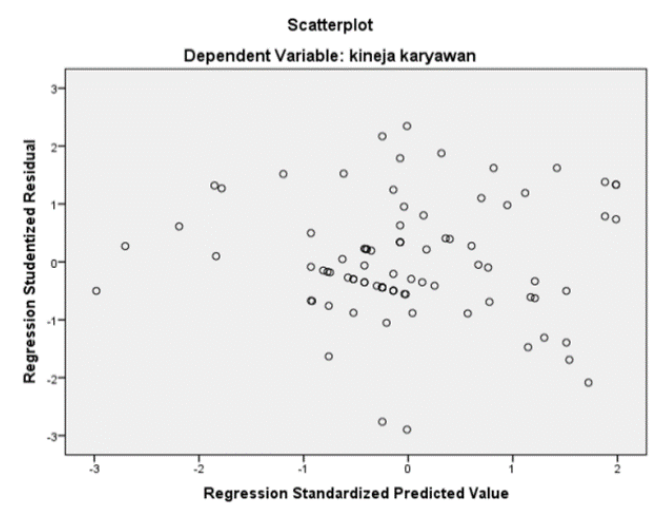

Gambar 1. Scatterplot

\section{Uji Hipotesis}

Pengujian hipotesis dimaksud-kan untuk menguji penerimaan dan penolakan dari rumusan hipotesis. Adapun rumusan hipotesisdalam penelitian ini adalah Rumusan hipotesisnya adalah:

Ho1: $\rho=0$ tidak ada pengaruh secara signifikan antara stres kerja dengan kinerja karyawan.

Ha1: $\rho \neq 0$ terdapat pengaruh secara signifikan antara stres kerja dengan kinerja karyawan.

Ho2: $\rho=0$ tidak ada pengaruh secara signifikan antara motivasi dengan kinerja karyawan.

Ha2: $\quad \rho \neq 0$ terdapat pengaruh secara signifikan antara motivasi dengan kinerja karyawan.
Ho3: $\rho=0$ tidak ada pengaruh secara signifikan antara stres kerja dan motivasi dengan kinerja karyawan.

Ha3: $\rho \neq 0$ terdapat pengaruh secara signifikan antara stres kerja dan motivasi dengan kinerja karyawan.

Dalam penelitian ini digunakan kriteria signifikansi $5 \% \quad(0,05)$ dengan membandingkan $t$ hitungdengan $t$ tabelyaitu sebagai berikut:

a. Jika $\mathrm{t}$ hitung $<\mathrm{t}$ tabel: berarti $\mathrm{H} 0$ diterima dan Ha ditolak $(a=5 \%)$

b. Jika $t$ hitung $>t$ tabel: berarti $\mathrm{H} 0$ ditolak dan Ha diterima $(\alpha=5 \%)$

Besarnya $t$ tabel dicari dengan menggunakan rumus: $\mathrm{df}=(\mathrm{n}-2$, maka diperoleh $(88-2)=86$ sehingga ttabel $=1,662$.

Tabel 2. Uji Hipotesis (Uji t)

Coefficients ${ }^{a}$

\begin{tabular}{|c|c|c|c|c|c|}
\hline \multirow[b]{2}{*}{ Model } & \multicolumn{2}{|c|}{ Unstandardized Coefficients } & \multirow{2}{*}{\begin{tabular}{|c} 
Standardized Coefficients \\
Beta
\end{tabular}} & \multirow[b]{2}{*}{$\mathrm{T}$} & \multirow[b]{2}{*}{ Sig. } \\
\hline & $\bar{B}$ & Std. Error & & & \\
\hline 1 Constant) & 25,476 & 3,700 & & 6,886 & ,000 \\
\hline stres kerja & ,095 & 100 & 11 & ,949 & ,345 \\
\hline Motivasi & ,306 & ,090 & 3 & 3,415 & ,001 \\
\hline
\end{tabular}


Tabel 3. Uji Statistik Simlutan (Uji F)

ANOVA $^{a}$

\begin{tabular}{|c|c|c|c|c|c|}
\hline Model & Sum of Squares & Df & Mean Square & $\mathrm{F}$ & Sig. \\
\hline 1 Regression & 280,496 & 2 & 140,248 & 11,660 &, $000^{\mathrm{b}}$ \\
\hline Residual & 1022,401 & 85 & 12,028 & & \\
\hline Total & 1302,898 & 87 & & & \\
\hline
\end{tabular}

Berdasarkan hasil output tabel diatas dapat dinilai F hitung sebesar 11,660 selanjutnya nilai ini akan dibandingkan dengan $\mathrm{F}$ tabel dengan nilai signifikansi $5 \%$, didapat $\mathrm{F}$ hitung lebih besar dari $\mathrm{F}$ tabel $(11,660>3.10)$ sehingga Ho diterima Ha ditolak, artinya terdapat pengaruh yang signifikan antara stres kerja (X1) dan motivasi (X2) dengan Kinerja Karyawan (Y) Di Hotel Santika Premiere ICE BSD-CITY.

\section{KESIMPULAN}

Dari hasil pembahasan yang telah dilakukan peneliti, maka peneliti memberikan beberapa kesimpulan sebagai berikut:

1. Stres kerja berpengaruh signifikan terhadap kinerja karyawan hal ini dapat dilihat dari hasil uji thitung $=0,949$ sedangkan ttabel $=1,662$ (thitung < ttabel) dengan taraf signifikansi 0,345 < 0,05, maka H0 diterima dan Ha ditolak. Hasil uji koefisien korelasi yang diperoleh berdasarkan angka koefisien korelasi antara stres kerja dan kinerja karyawan rendah atau sebesar 0.328 .

2. Motivasi berpengaruh signifikan secara parsial antara variabel motivasi tehadap kinerja karyawan dengan diperoleh nilai thitung $>$ ttabel atau $(3,415>1,662)$ hal ini diperkuat dengan nilai signifikansi 0,001 >0,05, maka Ho ditolak dan Ha diterima. Hasil uji koefisien korelasi yang diperoleh berdasarkan angka koefisien korelasi antara motivasi dan kinerja karyawan sedang atau sebesar 0.455 .

Secara simultan dengan uji $\mathrm{F}$ terdapat pengaruh yang positif dan signifikansi secara bersama-sama antara variabel stres kerja dan motivasi terhadap kinerja karyawan pada Hotel Santika Premiere ICE BSD-CITY dapat dilihat dari nilai yang diperoleh yaitu Fhitung $>$ Ftabel atau $(11,660>3.10)$ sehingga Ho diterima Ha ditolak, artinya terdapat pengaruh yang signifikan $0,000<0,05$.

\section{DAFTAR PUSTAKA}

Dewi, C, I, A, S \& Wibawa, I, M, A. (2016). Pengaruh Stres Kerja Dan Motivasi Kerja Terhadap Kinerja Karyawan Pada Pt. Bank Bpd Bali Cabang Ubud Jurnal Manajemen Universitas Udayana. $5(12)$.

Handoko, Hani. (2012). Manajemen Personalia dan Sumber Daya Manusia. Yogyakarta: BPFE.

Hasibuan, M. S.P. (2018). Manajmen Sumber Daya Manusia. Edisi Revisi, Jakarta: Bumi Aksara.

Hotiana, N \& Febriansyah. (2018). Pengaruh Motivasi Dan Stres Kerja Terhadap Kinerja Pegawai (Studi Pada Bagian Kepegawaian dan Organisasi, Biro Umum, Kepegawaian dan Organisasi Kementrian Pariwisata RI) Jurnal Riset Manajemen dan Bisnis. 3(1).

Luthfi, I, R,. Susilo, H \& Riza, M, F. (2014). Pengaruh Motivasi Terhadap Kinerja Karyawan (Studi Pada PT Elsiscom Prima Karya, Kantor Perwakilan Surabaya) Jurnal Administrasi Bisnis Fakultas Ilmu Administrasi Universitas Brawijaya Malang. 13(1).

Mangkunegara \& Anwar, P. (2011). Manajemen Sumber Daya Manusia Perusahaan. Remaja Rosdakarya Offset. Bandung.

Nurjaya, N., Erlangga, H., Hong, L. Z., \& Wijayanti, K. D. (2020). The Effect of Work Stress and Work Conflict on Employees Turnover Intention In Middle Small Micro Enterprises (MSMEs) In South Tangerang Region. International Journal of Educational Administration, Management, and Leadership, 51-62. 
Nurjaya, N., Sunarsi, D., Effendy, A. A., Teriyan, A., \& Gunartin, G. (2021). Pengaruh Etos Kerja Dan Disiplin Kerja Terhadap Kinerja Pegawai Pada Dinas Kehutanan Dan Perkebunan Kota Bogor. JENIUS (Jurnal Ilmiah Manajemen Sumber Daya Manusia), $4(2), 172-184$.

Prasada, D., Sunarsi, D., \& Teriyan, A. (2020). Pengaruh Etos Kerja Dan Kompensasi Terhadap Komitmen Organisasi Pada DHL Logistic Di Jakarta. JENIUS (Jurnal Ilmiah Manajemen Sumber Daya Manusia), $4(1), 51-60$.

Riandy. (2016). Pengaruh Stres Kerja Terhada Kinerja Karyawan Pada PT. Borneo Laboratorium Inspeksi Dan Surveyor Service Samarinda Jurnal Administrasi Bisnis Fakultas Ilmu Sosial dan Politik Universitas Mulawarman. $4(4)$

Rivai, V. (2014). Manajemen Sumber Daya Manusia. Jakarta: PT. Raja Grafindo Persada.

Sadili Samsudin. (2010). Manajemen Sumber Daya Manusia. Bandung: CV. Pustaka Setia.

Sarwani, S., Akbar, I. R., Handoko, A. L., \& Ilham, D. (2020). Pengaruh Pelatihan dan Motivasi terhadap Produktivitas Kerja Karyawan pada PT. Lion Mentari Airlines Bandara Internasional Soekarno Hatta Cengkareng. Jurnal Ilmu Komputer dan Bisnis, 11(2a), 91-100.

Sedarmayanti (2011).Tata Kerja dan Produktivitas Kerja.Bandung: CV Mandar Maju.

Sitepu, A, T. (2013). Beban kerja dan motivasi pengaruhnya terhadap kinerja karyawan pada PT. Bank Tabungan Negara Tbk Cabang
Manado Jurnal Emba Fakultas Ekonomi dan Bisnis, Jurusan Manajemen Universitas Sam Ratulangi Manado. 4(1).

Sofyan, S., Prasada, D., \& Akbar, I. R. (2020). Pengaruh Motivasi, Lingkungan Kerja dan Kepuasan Kerja Terhadap Kinerja Guru SMP/MTs Muhammadiyah Cabang Sawangan. Jurnal Ilmu Komputer dan Bisnis, 11(2a), 33-44.

Sugiyono. (2015). Penelitian Sumber Daya Manusia. Yogyakarta: CAPS.

Sunarsi, D. (2017). Pengaruh Kepemimpinan Dan Budaya Organisasi terhadap Kinerja Karyawan Pada Cabang Pembantu Bank DKI Pondok Labu-Jakarta Selatan. JENIUS, 1(2), 21.

Sunarsi, D. (2018). Pengaruh Kompensasi, Komunikasi Dan Stress Kerja Terhadap Prestasi Kerja Karyawan Pada PT Catur Putra Jaya Kota Depok-Jawa Barat. JIMF (Jurnal Ilmiah Manajemen Forkamma), 1(2).

Sutrisno, E. (2015). Manajemen Sumber Daya Manusia. Jakarta: Kencana Prenadamedia Group.

Sutrisno, Edy. (2012). Manajemen Sumber Daya Manusia. Edisi 1. Cetakan Keempat. Prenada Media Group. Jakarta

Tasril. (2015). Pengaruh Stres Dan Motivasi Kerja Terhadap Kinerja Pegawai Pada Seksi Perencanaan Bidang Bina Marga Dinas Pekerjaan Umum Provinsi Riau Jurnal Ilmiah Ekonomi dan Bisnis Fakultas ekonomi Universitas Lancang Kuning. 12. (2)

Wibowo. (2016). Manajemen Kinerja. Jakarta: PT. Raja Grafindo Persada. 